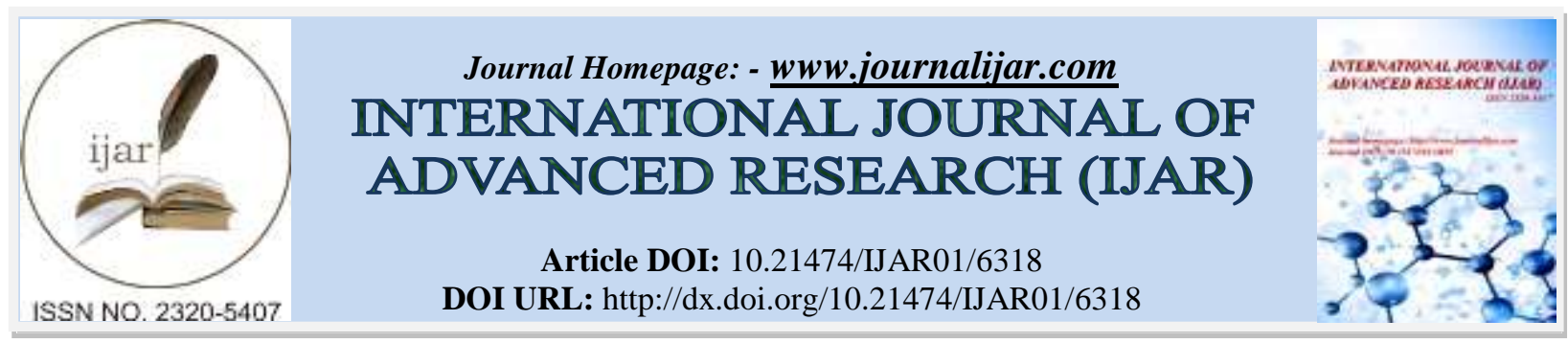

RESEARCH ARTICLE

\title{
INDULGENCE ON INTERNET DURING DUTY HOURS: AN IMMINENT THREAT TO DOCTOR- PATIENT RELATIONSHIP LEADING TO CONFLICTS-? POINT TO PONDER FOR MEDICAL WORLD!
}

\author{
Dr. Gopal Ashish Sharma and Dr. Sumala Kapila.
}

\section{Manuscript Info}

Manuscript History

Received: 15 November 2017

Final Accepted: 17 December 2017

Published: January 2018

\section{Abstract}

Copy Right, IJAR, 2018,. All rights reserved.

\section{Introduction:-}

Internet and its evolution over the time had led to an unprecedented cross exchanges of information and dissemination of knowledge at click of fingertip. India has the third largest Internet user base in the world and is expected to become the second largest this year. Similarly its, world's second largest telecom subscriber base only after China, with 933 million subscribers of which $97 \%$ are mobile subscribers ${ }^{i}$. With increase in life expectancy of average Indian in past decade and burgeoning population, it is expected that more number of patients will visit emergency department as evidenced in the published literature also ${ }^{\text {ii }}$. Moreover in recent pasts , there are increased number of incidents of violence reported against medical professionals almost on daily basis across India and some of assaults resulting in life threatening injuries to service providers. This brings to forth the pertinent question of doctor-patient relationship into focus of attention.

It is a well established fact that effective doctor-patient communication is a central clinical function in building a therapeutic doctor-patient relationship, which is the heart and art of medicine ${ }^{\mathrm{iii}}$. Effective, transparent communication along with empathy for patient or caregivers can pave way for optimal desired outcomes for all stakeholders. Aspects of patient-doctor communication such as 'receiving an explanation for the occurrence of the symptom/ sign, likely duration of treatment and the lack of unmet expectations were found to be key predictors of patient satisfaction ${ }^{\text {iv }}$. Although conflicts and assault have been attributed to multi factorial components like over burdened healthcare institutions particularly at government sector, long waiting time to meet doctors, low literacy levels of caregivers, non availability of competent human resources cum dysfunctional logistics etc. But at the same time warrants for another emerging aspect of barrier to communication that is over indulgence with personal handsets/mobiles as a sequel of uninterrupted internet connectivity.

With rapid penetration of internet connectivity amongst the general population of India, there are greater chances that one or other person might be using their mobile phones concurrently or otherwise. At same time it is also an established fact that cell phone conversations may be a common source of distraction causing negative consequences in workplace environments and other public places ${ }^{\mathrm{v}}$. Whenever a patient approaches a doctor,the utmost desired expectancy of patient is complete attention from the doctor for his ailments.In recently released Microsoft Attention Spans Research Report it was revealed that the average human attention span has decreased from 12 seconds to 8 seconds since 2000 less than even goldfish ${ }^{\mathrm{vi}}$. Moreover 52\% of respondents age group (18-24) had reported that 
they check their phone at least every 30 minutes. This is the area of prime concern for medical professionals ,with the advent of technology and 24 hour free internet connectivity attention of service provider from patient probably might get diverted in between due to some post/alert of an app. This itself raises many questions in caregivers perception about quality of service being provided. Particularly in scenario of emergency if same behavior is repeated number of time it can lead to tipping point which can trigger serious conflicts amongst doctor, patients and caregivers on site.

Poor inter personal communication amongst doctor and patient is an important reason cited for rising incidents of violence against medical professionals in India. Rising incidents of violence and conflicts had forced many state governments to have some kind of Medicare Service Person Acts notified in the past few years. But remedial solutions lies some where else in our medical curriculum. Till date, medical curriculum and training programs have been designed around specific educational or learning objectives addressing primarily three domains: Cognitive, psychomotor and affective, also known as the head, and hand and heart, respectively. However, currently, medical education in India deals greatly with the head, meagerly with the hand, and nearly neglects the heart, thus failing to produce a clinician who would understand and provide holistic care (i.e., preventive, promotive, curative, and palliative care) with compassion ${ }^{\text {vii }}$. Budding graduates must be taught about clinical skills along with ever important behavioral life skill of "empathy" in context of communication in this newer virtual world of connectivity .

Although proposed ATCOM model of MCI specifically addresses the communication and Doctor-patient relationship, but need of hour is to stress upon empathy amongst newer graduates at medical college level on day to day basis during course. To conclude there is a famous quote by Terry Canale in his American Academy of Orthopaedic Surgeons Vice Presidential Address ${ }^{\text {viii }}$.

“The patient will never care how much you know, until they know how much you care." Medical professionals need to express their much needed attention to patients/caregivers leaving aside the nagging distractions of this virtual world of connectivity.

${ }^{\mathrm{i}}$ India on the Go: Mobile Internet Vision 2017 A study by KPMG - IAMAI July 2015 Available from https://ultra.news/wp-content/uploads/2015/07/Report.pdf last accessed on $21^{\text {ST }}$ January,2018

${ }^{i i}$ Overcrowding in emergency departments: Increased demand and decreased capacity Derlet, Robert W.Annals of Emergency Medicine, Volume 39, Issue 4, 430 - 432

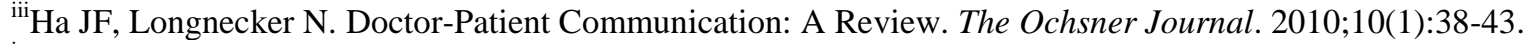

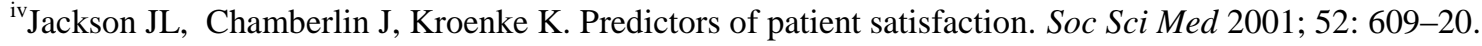

${ }^{v}$ Galva'n VV, Vessal RS, Golley MT (2013) The Effects of Cell Phone Conversations on the Attention and Memory of Bystanders. PLoS ONE 8(3): e58579. doi:10.1371/journal.pone.0058579

vi Microsoft ATtENTION SPANS RESEARCH REPORT HTTPS://WWW.SCRIBD.COM/DOCUMENT/265348695/MICROSOFT-ATTENTION-SPANS-RESEARCH-REPORT\#DOWNLOAD LAST ACCESSED ON $24^{\mathrm{TH}}$ JANUARY ,2018

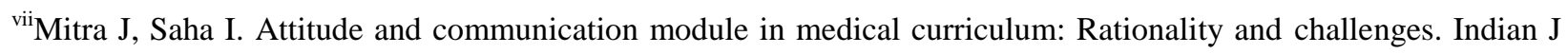
Public Health 2016;60:95-8

viii Tongue J. R., Epps H. R., Forese L. L. Communication skills for patient-centered care: research-based, easily learned techniques for medical interviews that benefit orthopaedic surgeons and their patients. J Bone Joint Surg Am. 2005;87:652-658. 